\title{
Extensive polymorphism and chromosomal characteristics of ribosomal DNA in the characid fish Triportheus venezuelensis (Characiformes, Characidae)
}

\author{
Mauro Nirchio ${ }^{1}$, Claudio Oliveira ${ }^{2}$, Irani Alves Ferreira ${ }^{2}$, Angel Granado ${ }^{1}$ and Ernesto Ron ${ }^{3}$ \\ ${ }^{1}$ Escuela de Ciencias Aplicadas del Mar, Universidad de Oriente, Isla de Margarita, Venezuela. \\ ${ }^{2}$ Departamento de Morfologia, Instituto de Biociências, Universidade Estadual Paulista, Botucatu, \\ São Paulo, Brazil. \\ ${ }^{3}$ Instituto Limnológico, Universidad de Oriente, Caicara del Orinoco, Bolivar, Venezuela.
}

\begin{abstract}
The karyotype and chromosomal characteristics of the characid fish Triportheus venezuelensis were investigated using differential staining techniques (C-banding, Ag-NOR staining) and fluorescent in situ hybridization (FISH) with an $18 S$ rDNA probe. The diploid chromosome number $(2 n=52)$, karyotype composition and sex chromosome determination system of the ZZ/ZW type were the same as previously described in other species of the genus Triportheus. However, extensive variation regarding nucleolus organizer regions (NOR) different from other species was observed. 18S rDNA sequences were distributed on nine chromosome pairs, but the number of chromosomes with Ag-NORs was usually lower, reaching a maximum of four chromosomes. When sequential staining experiments were performed, it was demonstrated that: 1.) active NORs usually corresponded to segments with 18S rDNA genes identified in FISH experiments; 2.) several $18 \mathrm{~S}$ rDNA sequences were not silver-stained, suggesting that they do not correspond to active NORs; and 3.) some chromosomes with silver-stained regions did not display any 18S rDNA signals. These findings characterize an extensive polymorphism associated with the NOR-bearing chromosomes of $T$. venezuelensis and emphasize the importance of combining traditional and molecular techniques in chromosome studies.
\end{abstract}

Key words: 18S rDNA, Ag-NORs, C-band, FISH, fish cytogenetics, sex chromosomes.

Received: September 1, 2005; Accepted: May 17, 2006.

\section{Introduction}

Two distinct sets of multiple rRNA genes, usually located on distinct chromosomes, operate in eukaryote genomes: the $18 \mathrm{~S}, 5.8 \mathrm{~S}$ and $28 \mathrm{~S}$ major genes and the $5 \mathrm{~S}$ minor genes (Hadjiolov, 1985). The eukaryotic major rRNA genes are grouped, in order to form RNA polymerase I transcription units, and multiple copies of these units are typically found clustered in long direct tandem arrays cytologically identified as the nucleolus organizer regions (NORs) (Hadjiolov, 1985; Drouin and Moniz-de-Sá, 1995).

The chromosomal sites of the major rRNA genes has been localized using isotopic in situ hybridization, fluorochrome dyes, N-banding, silver staining, immunofluorescence, and more recently by means of fluorescent in situ hybridization (FISH) using specific probes (Sumner,

Send correspondence to Claudio Oliveira. Departamento de Morfologia, Instituto de Biociências, Universidade Estadual Paulista, 18618-000 Botucatu, São Paulo, Brazil. E-mail: claudio@ibb. unesp.br.
1990). However, the technique most commonly used to detected NORs is the silver nitrate $(\mathrm{Ag})$ impregnation method in which silver binds to NOR proteins such as the RNA polymerase I subunit which is part of the active site of ribosomal genes (Roussel and Hernandez-Verdun, 1994; Whitehead et al., 1997). Unfortunately, silver nitrate may also bind to other proteins present in the nuclei, thus some chromosome structures visualized by silver nitrate may not correspond to ribosomal genes (Dobigny et al., 2002).

The Characidae is a large and diversified family of fish that contains 167 genera and 980 species (Reis et al., 2003), including members of the genus Triportheus which has 16 species widely distributed in South America (Malabarba, 2004). Members of the genus Triportheus possess karyotypes characterized by a constant diploid number of $2 \mathrm{n}=52$ and a relatively conserved chromosome complement, as well as by the presence of a zz/zw sex chromosome system (Bertollo and Cavallaro, 1992; Sánchez and Jorge, 1999; Artoni et al., 2001; Artoni and Bertollo, 2002).

We used silver-staining and FISH with a $18 \mathrm{~S}$ rDNA probe to investigate the karyotype of Triportheus 
venezuelensis and the distribution of the major rDNA gene cluster with the objective of characterizing the number, distribution, and degree of activity of these genes in this species.

\section{Material and Methods}

We captured 8 female and 8 male $(\mathrm{n}=16)$ Triportheus venezuelensis Spix, 1829 in Castillero Lake (Laguna de Castillero) Caicara del Orinoco, Bolívar State, Venezuela. Voucher specimens were deposited in the fish collection of Escuela de Ciencias Aplicadas del Mar, Universidad de Oriente, Nueva Esparta, Venezuela and the Labortatório de Biologia e Genética de Peixes (LBP 2194 and LBP 2230), Universidade Estadual Paulista, São Paulo, Brazil.
Mitotic chromosome preparations were obtained from kidney and gill tissues using the air-drying technique of Foresti et al. (1993). Chromosome morphology was determined on the basis of arm ratio, as proposed by Levan et al. (1964), and chromosomes were classified as metacentric (M), submetacentric (SM), subtelocentric (ST), and acrocentric (A). The NORs were identified by silver staining (Ag-NORs), as described by Howell and Black (1980) and C-banding was performed according to Sumner (1972). The FISH experiments were performed according to Pinkel et al. (1996). A tilapia (Oreochromis niloticus) 18S rDNA sequence (about 1800 base pairs) cloned in pGEM-T was labeled by nick translation with biotin-14-dATP according to the manufacturer's instructions (Bionick Labelling System-Gibco. BRL). The 18S rDNA sequences were located in the chromosomes with Avidin-N-fluorescein

a
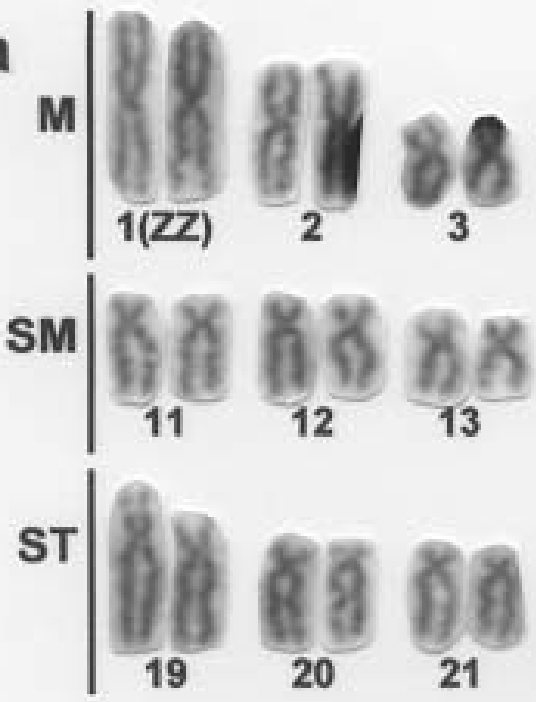

b
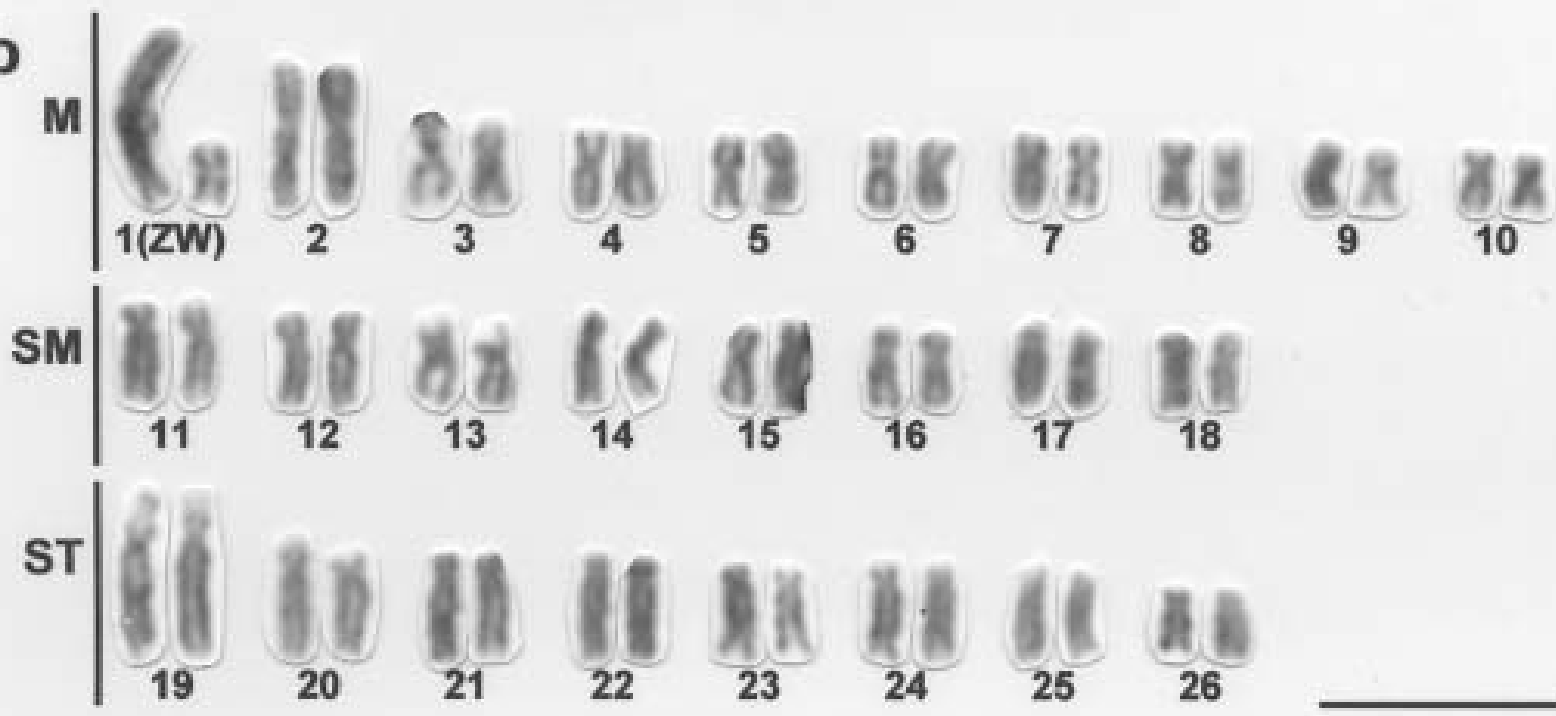

Figure 1 - Giemsa stained karyotypes of a male (a) and a female (b) Triportheus venezuelensis. Bar $=10 \mu \mathrm{m}$. 
Isothiocyanate (FITC) conjugate and the signal enhanced using biotinylated Anti-avidin goat antibodies following a second round of Avidin-FITC detection. Chromosomes were counter-stained with Propidium Iodide $\left(50 \mu \mathrm{g} \mathrm{mL}^{-1}\right)$ diluted in Antifade. Metaphases were examined in a Zeiss Axiophot photomicroscope and pictures were taken with Kodak Gold Ultra 400 ASA film.

\section{Results}

The diploid chromosome number for both sexes was $2 n=52$. The male karyotype was $20 \mathrm{M}, 16 \mathrm{SM}$ and $16 \mathrm{ST}$ chromosomes, where the largest metacentric pair (pair 1) represented the sex chromosomes (Figure 1). The female karyotype was the same as in the males except that pair 1 was composed of one large metacentric (the $\mathrm{Z}$ chromosome) and one small metacentric (the $\mathrm{W}$ chromosome) (Figure 1b). Small C-band positive heterochromatic segments were present at the centromeres of almost all chromosomes of both males (not shown) and females (Figure 2). The long arm of the $\mathrm{Z}$ chromosomes and the whole $\mathrm{W}$ chromosome were entirely $\mathrm{C}$-band positive; the short arms of the chromosome pair 19 were also almost entirely C-band positive (Figure 2).

FISH with $18 \mathrm{~S}$ rDNA probe showed that the $18 \mathrm{~S}$ rDNA sites were distributed over nine chromosomes pairs (pairs 1, 6, 7, 11, 12, 18, 19, 20 and 21; Figures 3 and 4): 1.) at the end of the long arm of the $\mathrm{W}$ chromosome (pair 1);2.) on the long arm of a small-sized metacentric chromosome (pair 6); 3.) on both chromosome arms of a small-sized metacentric pair (pair 7); 4.) on the long arm of two large sub-metacentric pairs (pairs 11 and 12); 5.) on the long arm of a small sub-metacentric pair (pair 18); 6) on the short arm of the two largest subtelocentric chromosomes (pairs

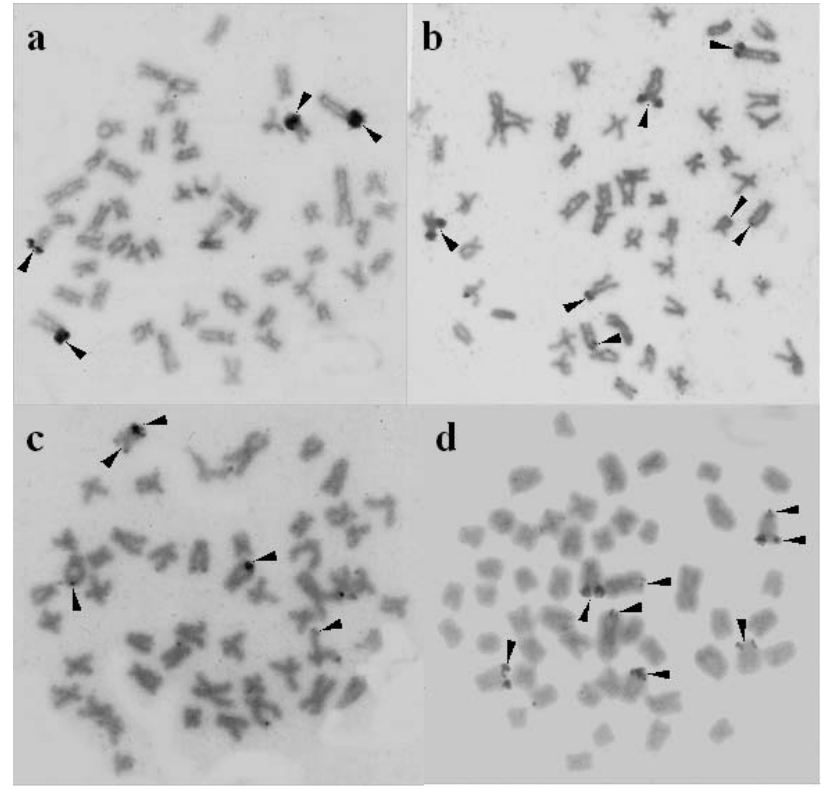

Figure 3 - Chromosome metaphase spreads of Triportheus venezuelensis. FISH probed with $18 \mathrm{~S}$ rDNA. The original colors were artificially transformed. Arrows indicate the detected loci.

19 and 20), 7) and on both arms of a large subtelocentric chromosome pair (pair 21). Chromosome pairs 6 and 7, as well as 20 and 21 , were very similar, differing only by the presence of additional $18 \mathrm{~S}$ sites on the pairs 7 and 21 (Figure 4).

Silver-staining showed that the number of chromosomes with Ag-NORs was usually lower than the number of chromosomes with $18 \mathrm{~S}$ rDNA regions (Table 1). The chromosomes with positive signals after silver-staining were pairs $6,11,12,18$ and 19 (Table 1). The most frequently observed chromosome pair with positive Ag-NORs

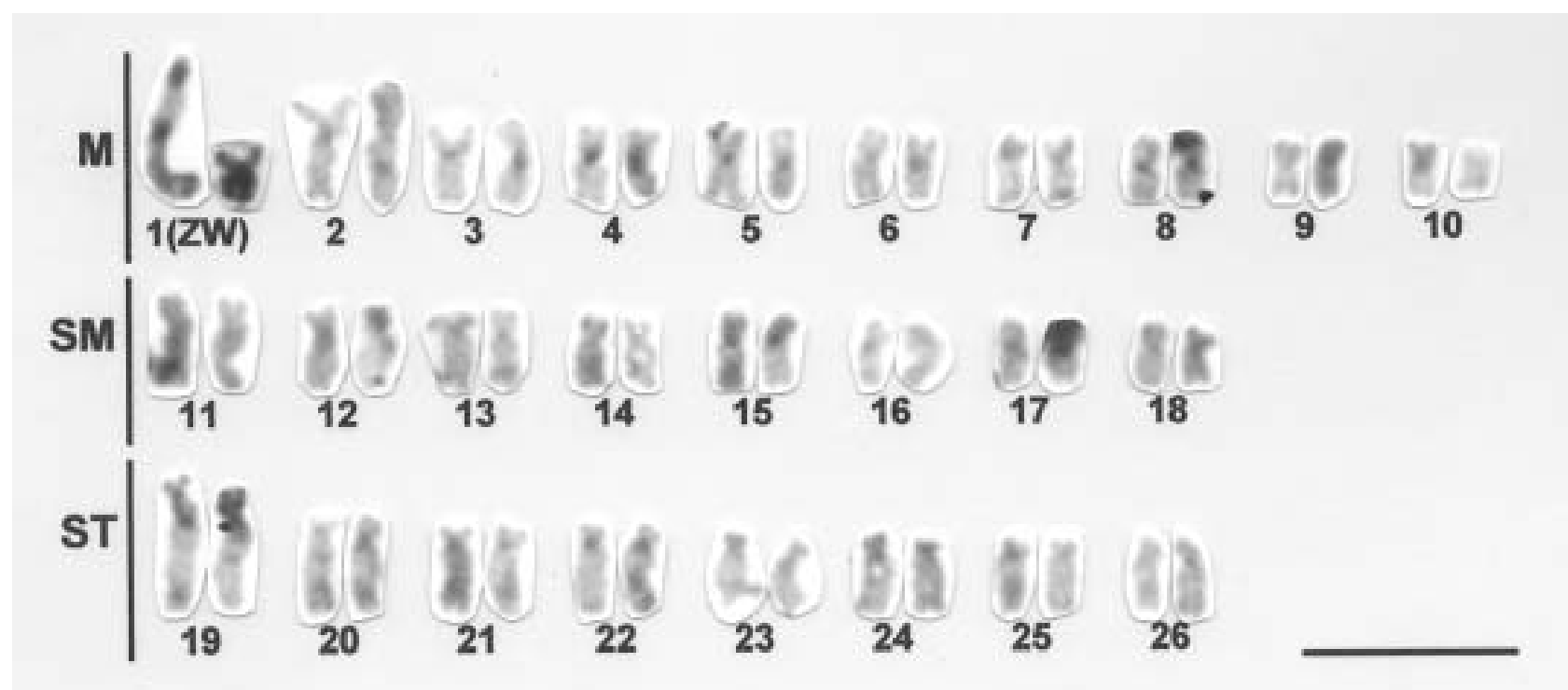

Figure 2 - C-banded karyotype of a female Triportheus venezuelensis. Bar $=10 \mu \mathrm{m}$. 


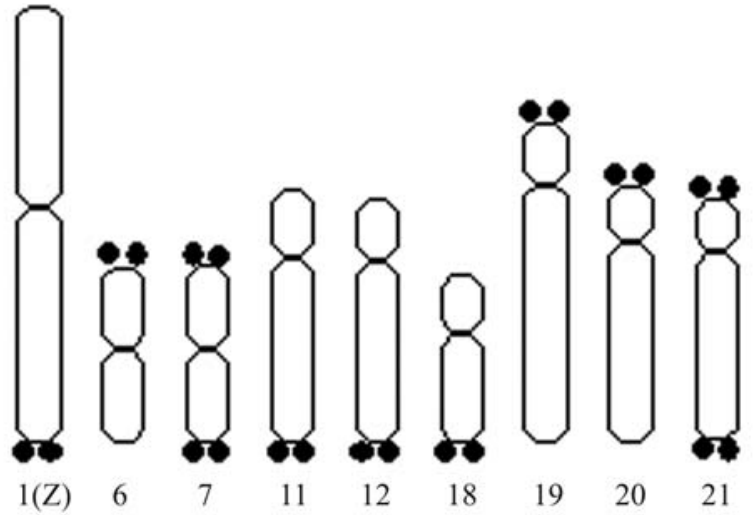

Figure 4 - Ideogram representing the physical mapping of 18S rDNA genes (indicated as black dots) in the chromosomes of Triportheus venezuelensis.

was pair 19 , identified in $81 \%$ of the specimens analyzed ( 6 females and 7 males), which was the only active pair in $50 \%$ of the fish analyzed ( 2 females and 6 males).

Sequential silver-staining and FISH probing demonstrated that: 1.) positive NOR sites usually correspond to segments with 18S rDNA sites; 2.) several 18S rDNA sites were not silver-stained, suggesting that they do not correspond to active NORs; and 3.) some chromosomes with positive silver-signals do not display the presence of $18 \mathrm{~S}$ rDNA sites (see Table 1, specimens 3, 6 and 9 and Figure 5).

\section{Discussion}

Previous cytogenetic studies on Triportheus have shown that all species possess a chromosome complement of $2 n=52$ and a ZZ/ZW heteromorphic sex chromosome system (Bertollo and Cavallaro, 1992; Sánchez and Jorge, 1999; Artoni et al., 2001; Artoni and Bertollo, 2002). We confirmed this in $T$. venezuelensis, reinforcing the hypothesis that this group represents a monophyletic unit in the Characidae (Malabarba, 2004).

The $\mathrm{Z}$ chromosome of $T$. venezuelensis displayed an entirely C-band positive longer arm, a characteristic not yet described in other Triportheus species (Artoni et al., 2001). The $\mathrm{W}$ chromosome was $\mathrm{C}$-band positive throughout all its length, similar to what has been reported for other Triportheus species (Artoni et al., 2001), with small differences in the extension of the distribution of C-band positive segments. The heterochromatinization of the $\mathrm{W}$ chromosome in the Triportheus is thought to be associated with a reduction in the size of this chromosome during the evolution of the ZW sex chromosome system (Bertollo and Cavallaro, 1992; Artoni et al., 2001), but a robust phylogeny to test this hypothesis is still lacking for the group. The presence of an entirely C-heterochromatin positive $\mathrm{W}$ chromosome has also been reported in Characidium gomesi (Maistro et al., 2004) and C-heterochromatin positive segments associated with $\mathrm{W}$ or $\mathrm{Y}$ chromosomes have been de-
Table 1 - Distribution of Ag-NOR-bearing chromosomes and 18S rDNA-bearing chromosomes in specimens of Triportheus venezuelensis. Chromosomes are identified as in Figure 4.

\begin{tabular}{|c|c|c|c|c|c|}
\hline \multirow[t]{2}{*}{ Animal } & \multicolumn{3}{|c|}{ Chromosome with } & \multicolumn{2}{|c|}{ Chromosome with } \\
\hline & Sex & Ag - NORs & Total & 188 rDNA & Total \\
\hline 1 & q & \& \& & 2 & Q८०८ & 4 \\
\hline 2 & 우 & 80 & 2 & 088 & 3 \\
\hline 3 & q & QQ४Q & 4 & QQใ & 4 \\
\hline 4 & q & $B B_{B}$ & 3 & OQBB & 4 \\
\hline 5 & q & OB 8 & 3 & $\mathrm{OPB}$ & 3 \\
\hline 6 & 우 & QB 8 & 3 & ดQด & 4 \\
\hline 7 & q & OB & 3 & OQBB & 4 \\
\hline 8 & 우 & 60 & 2 & OOBOBBB & 7 \\
\hline 9 & o & 88.98 & 4 & OBB & 4 \\
\hline 10 & 8 & 08 & 2 & OQBQ & 4 \\
\hline 11 & o & 80 & 2 & ODB & 3 \\
\hline 12 & 3 & 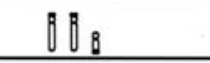 & 3 & $O D_{B}$ & 3 \\
\hline 13 & o & of & 2 & QOBBQBB & 7 \\
\hline 14 & $\sigma^{2}$ & 08 & 2 & DDBB & 4 \\
\hline 15 & o & 08 & 2 & 00 & 2 \\
\hline 16 & $\delta$ & 08 & 2 & OAB & 4 \\
\hline
\end{tabular}

scribed in several fish species, reinforcing the possible important role of heterochromatinization in sex chromosome development in lower vertebrates (Almeida-Toledo et al., 2000; Devlin and Nagahama, 2002).

In the karyotypes of representatives of the genus Triportheus, the presence of only one pair of NOR-bearing elements ( e.g. pair 18) has been reported by Artoni and Bertollo (2002), a characteristic that was considered evolutionarily conserved in the genus. However, extensive cytogenetic screening in Triportheus guentheri by Bertollo and Cavallaro (1992) has shown that although T. guentheri karyotype usually had one Ag-NOR-bearing chromosome pair additional signals were occasionally observed on a second autosomal pair and on the $\mathrm{Z}$ chromosome. Our study showed that the $T$. venezuelensis specimens displayed a very conspicuous polymorphism associated with the number of major rDNA sites. The combination of silverstaining and $18 \mathrm{~S}$ rDNA FISH showed that one chromosome pair (probably pair 19) nearly always had the Agpositive NORs in this species. However, other chromosome pairs also had Ag-positive NORs, and some had 18S rDNA sites but did not display positive signals after silver-staining. 


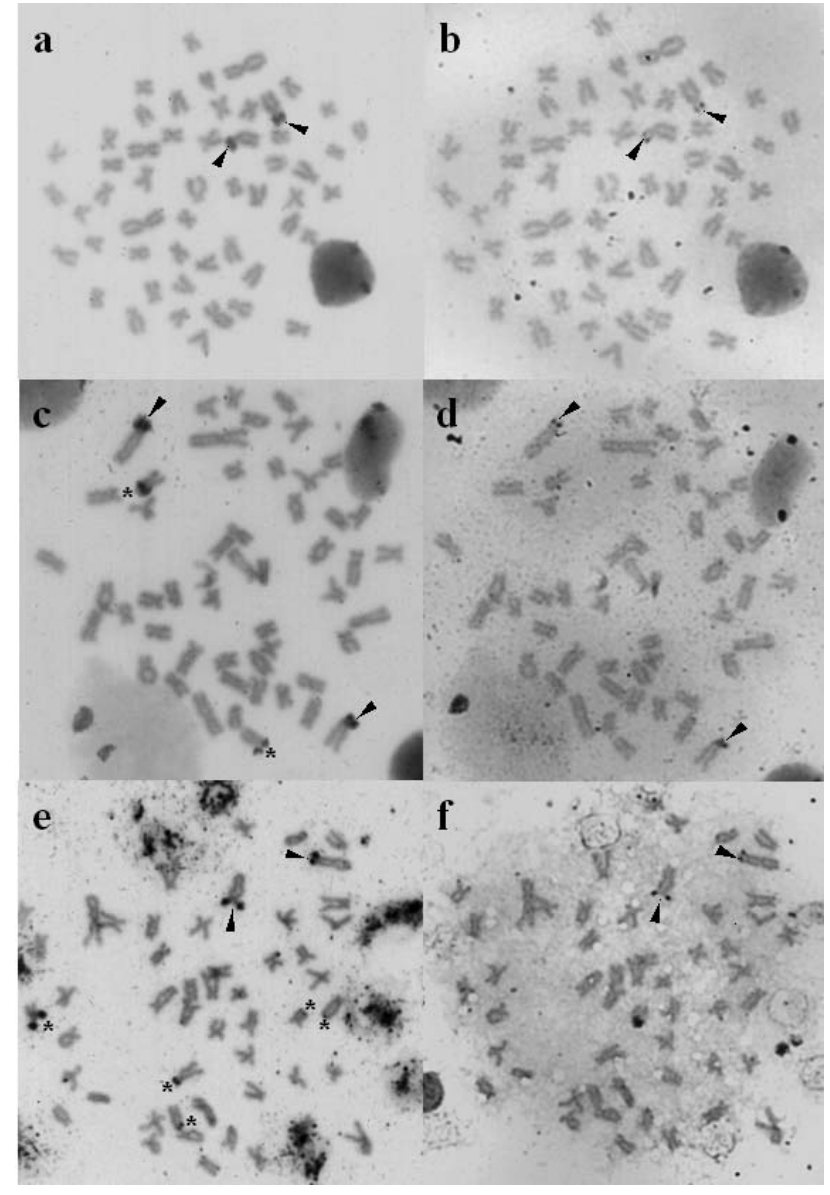

Figure 5 - Metaphases of Triportheus venezuelensis sequentially stained with the FISH technique using an $18 \mathrm{~S}$ rDNA probe (a, c, e - the original colors were artificially transformed) and with the Ag-NOR technique (b, d, f). Arrows point active Ag-NOR. Asterisks show segments identified with the $18 \mathrm{~S}$ rDNA probe and not stained in the silver staining experiments.

Studies conducted in fishes have shown that in some species, e.g. Lepisosteus osseus (Ráb et al., 1999), with only one Ag-NOR-bearing chromosome pair, the FISH technique using $18 \mathrm{~S}$ or $28 \mathrm{~S}$ sequences usually stains the same chromosome pair. Nevertheless, the presence of a number of major ribosomal cistrons identified by the FISH technique using $18 \mathrm{~S}$ or $28 \mathrm{~S}$ sequences higher than that observed with the Ag-NOR technique are more common, having been reported in Salmo truta (Pendás et al., 1993), Astyanax scabripinnis (Ferro et al., 2001), Hyphessobrycon anisitsi (Centofante et al., 2003), Prochilodus lineatus (Jesus and Moreira-Filho, 2003), Colossoma macropomum, Piaractus brachypomus and its interspecific hybrids (Nirchio et al., 2003), and Lebias fasciata (Tigano et al., 2004). These differences have been attributed to the presence of NORs that are usually unexpressed.

Recent studies conducted with human and chimpanzee cells showed that three mechanisms produce inactivation of NORs: 1.) elimination of rDNA; 2.) DNA methylation; and 3.) gene silencing due to positional effects induced by heterochromatin (C-bands) and/or telomeres (Guillén et al., 2004). Our results suggest that in $T$. venezuelensis the elimination of rDNA sequences is the most frequent rearrangement involved in NOR inactivation. Gene silencing due to positional effects does not seem to occur, since the more common pair of chromosome with active NORs is pair 19, which has a conspicuous C-band positive segment in the same position as the NORs. The occurrence of DNA methylation was not investigated in our present study.

An unusual finding in our study was the presence of putative active NORs that were not detected by the FISH technique. One hypothesis to explain these data is that silver might be staining proteins not related to NORs, the existence of some nuclear proteins with silver-affinity have been reported by several authors (Sumner, 1990; Dobigny et al., 2002). However, the chromosomes with Ag-NORsstained in the specimens 3, 6 and 9 were usually found to bear $18 \mathrm{~S}$ genes in the other specimens, leading to an alternative hypothesis suggesting that specimens 3, 6 and 9 might have a very small copy number of major NOR genes not detectable with FISH but observable after intense transcription or as a result of gene amplification. If this second hypothesis is correct, the use of the silver-staining technique to study NORs may be more important than is currently believed.

\section{Acknowledgments}

The authors are grateful to Maria Cláudia S.L. Malabarba for the taxonomic identification of the specimens. Funds supporting this study were provided by Consejo de Investigación-UDO and the Brazilian agencies CNPq and FAPESP.

\section{References}

Almeida-Toledo LF, Foresti F and Toledo-Filho SA (2000) Karyotypic evolution in Neotropical freshwater fish. Chrom Today 13:169-182.

Artoni RF and Bertollo LAC (2002) Evolutionary aspects of the ZZ/ZW sex chromosome system in the Characidae fish, genus Triportheus. A Monophyletic state and NOR location on the W chromosome. Heredity 89:15-19.

Artoni RF, Falcão JN, Moreira-Filho O and Bertollo LAC (2001) An uncommon condition for a sex chromosome system in Characidae fish. Distribution and differentiation of the zz/zw system in Triportheus. Chromosome Res 9:449-456.

Bertollo LAC and Cavallaro ZI (1992) A highly differentiated ZZ/ZW sex chromosome system in a Characidae fish Triportheus guentheri. Cytogenet Cell Genet 60:60-63.

Centofante L, Bertollo LAC, Miyazawa CS and Moreira-Filho O (2003) Chromosomal differentiation among allopatric populations of Hyphessobrycon anisitsi (Pisces, Tetragonopterinae). Cytology 68:283-288. 
Devlin RH and Nagahama Y (2002) Sex determination and sex differentiation in fish: an overview of genetic, physiological, and environmental influences. Aquaculture 208:191-364.

Dobigny G, Ozouf-Costaz C, Bonillo C and Volobouev V (2002) "Ag-NORs" are not always true NORs: New evidence in mammals. Cytogenet Genome Res 98:75-77.

Drouin G and Muniz-de-Sá M (1995) The concerted evolution of $5 \mathrm{~S}$ ribosomal genes linked to the repeat units of other multigene families. Mol Biol Evol 12:481-493.

Ferro DAM, Neo DM, Moreira-Filho O and Bertollo LAC (2001) Nucleolar organizing regions, $18 \mathrm{~S}$ and $5 \mathrm{~S}$ rDNA in Astyanax scabripinnis (Pisces, Characidae): Populations distribution and functional diversity. Genetica 110:55-62.

Foresti F, Oliveira C and Almeida-Toledo LF (1993) A method for chromosome preparations from large specimens of fishes using in vitro short treatment with colchicine. Experientia 49:810-813.

Guillén AKZ, Hirai Y, Tanoue T and Hirai H (2004) Transcriptional repression mechanisms of nucleolus organizer regions (NORs) in humans and chimpanzees. Chromosome Res 12:225-237.

Hadjiolov AA (1985) The nucleolus and ribosome biogenesis. Springer-Verlag, New York, 263 pp.

Howell WM and Black DA (1980) Controlled silver staining of nucleolus organizer regions with a protective colloidal developer: A 1-step method. Experientia 3:1014-1015.

Jesus CM and Moreira-Filho O (2003) Chromosomal location of $5 \mathrm{~S}$ and $18 \mathrm{~S}$ rRNA genes in Prochilodus lineatus (Characiformes, Prochilodontidae). Caryologia 56:281-287.

Levan A, Fredga A and Sandburg A (1964) Nomenclature for centromeric position on chromosomes. Hereditas 52:201220 .

Maistro EL, Jesus CM, Oliveira C, Moreira-Filho O and Foresti F (2004) Cytogenetic analysis of A-, B-chromosomes and ZZ/ZW sex chromosomes of Characidium gomesi (Teleostei, Characiformes, Crenuchidae). Cytologia 69:181186.

Malabarba MCSL (2004) Revision of the Neotropical genus Triportheus Cope, 1872 (Characiformes, Characidae). Neotropical Ichthyol 2:167-204.
Nirchio M, Fenocchio AS, Swarça AC, Pérez JE, Granado A, Estrada A and Ron E (2003) Cytogenetic characterization of hybrids offspring between Colossoma macropomum (Cuvier, 1818) and Piaractus brachypomus (Cuvier, 1817) from Caicara del Orinoco, Venezuela. Caryologia 56:405-411.

Pendás AM, Móran P and García-Vasquez E (1993) Ribosomal rna genes are interspersed throughout heterochromatin chromosome arms in Atlantic salmon. Cytogenet Cell Genet 63:128-130.

Pinkel D, Straume T and Gray JW (1986) Cytogenetic analysis using quantitative, high-sensitivity, fluorescence hybridization. Proc Natl Acad Sci USA 83:2934-2938.

Ráb P, Rábová M, Reed KM and Phillips RB (1999) Chromosomal characteristics of ribosomal DNA in the primitive semionotiform fish, Lepisosteus osseus. Chromosome Res 7:475-480.

Reis RE, Kullander SO and Ferraris C (2003) Check List of the Freshwater Fishes of South and Central America. EDIPUCRS, Porto Alegre, 729 pp.

Roussel P and Hernandez-Verdun D (1994) Identification of AgNOR proteins, markers of proliferation related to ribosomal gene activity. Exp Cell Res 214:465-472.

Sanchez S and Jorge LC (1999) A new report of the ZZ/ZW sex chromosome system in the genus Triportheus (Pisces, Triportheinae). Cytologia 64:395-400.

Sumner AT (1972) A simple technique for demonstrating centromeric heterochromatin. Exp Cell Res 75:304-306.

Sumner AT (1990) Chromosome Banding. Unwin Hyman Inc., Cambridge, $434 \mathrm{pp}$.

Tigano C, Rocco L, Ferrito V, Costagliola D, Pappalardo AM and Stingo V (2004) Chromosome mapping and molecular characterization of ribosomal RNA genes in Lebias fasciata (Teleostei, Cyprinodontidae). Genetica 121:95-100.

Whitehead CM, Winkfein RJ, Fritzler MJ and Rattner JB (1997) ASE-1: A novel protein of the fibrillar centers of the nucleolus and nucleolus organizer region of mitotic chromosomes. Chromosoma 106:493-502.

Associate Editor: Fausto Foresti 